\title{
DSK1, a Kinesin-Related Protein Involved in Anaphase Spindle Elongation, Is a Component of a Mitotic Spindle Matrix
}

\author{
Harrison Wein, ${ }^{1}$ Hank W. Bass,${ }^{2}$ and W. Zacheus Cande ${ }^{3 *}$ \\ ${ }^{1}$ Federation of American Scientists, Washington, DC \\ ${ }^{2}$ Department of Biological Sciences, Florida State University, Tallahassee \\ ${ }^{3}$ Department of Molecular and Cell Biology, University of California, Berkeley
}

\begin{abstract}
DSK1 is a kinesin-related protein that is involved in anaphase spindle elongation in the diatom Cylindrotheca fusiformis [Wein et al., 1996: J. Cell Biol. 113:595-604]. DSK1 staining appeared to be concentrated in the gap that forms as the two half-spindles separate, suggesting that DSK1 may be part of a non-microtubule spindle matrix. We set out to investigate this possibility using three-dimensional high-resolution fluorescence microscopy, and biochemical methods of tubulin extraction. Three-dimensional fluorescence microscopy reveals that DSK1 remains in the midzone after the bulk of the microtubules from the two half-spindles have left the region. Biochemical studies show that $\mathrm{CaCl}_{2}$ extraction of tubulin from a mitotic spindle preparation does not extract similar proportions of DSK1 protein. Immunofluorescence confirms that this $\mathrm{CaCl}_{2}$ extraction leaves behind spindle-like bars that are recognized by anti-DSK1, but not by anti-tubulin antibodies. We conclude that DSK1 is part of, or attached to, a non-microtubule scaffold in the diatom central spindle. This discovery has implications for both the structural organization of the mitotic spindle and the mechanism of spindle elongation. Cell Motil. Cytoskeleton 41:214-224, 1998. @ 1998 Wiley-Liss, Inc.
\end{abstract}

Key words: mitosis; kinesin-related protein; diatom; mitotic spindle matrix

\section{INTRODUCTION}

In diatoms, the movements associated with anaphase A (chromosome-to-pole movement) and anaphase $\mathrm{B}$ (spindle elongation) are structurally separated in space: the chromosomes and kinetochore microtubules (MTs) involved in anaphase A form a loose cone around the central spindle, the structure responsible for anaphase B [McDonald et al., 1977, 1979; Pickett-Heaps and Tippit, 1978; McIntosh et al., 1979]. The diatom central spindle is an unusually highly ordered paracrystalline array of microtubules [McDonald et al., 1977, 1979; PickettHeaps and Tippit, 1978; McIntosh et al., 1979; McDonald and Cande, 1989]. The microtubules in each half of the central spindle interdigitate to form a well-defined region of antiparallel MT overlap that is generally referred to as the spindle midzone. The high level of organization in the diatom central spindle helps to render them remarkably stable, and therefore ideal for studying the mechanism of spindle elongation.
DSK1 (Diatom Spindle Kinesin 1) was originally isolated from a $C$. fusiformis cDNA expression library by screening with a peptide antibody raised against a conserved region in the motor domain of the kinesin superfamily [Wein et al., 1996]. By sequence homology, DSK1 belongs to the central motor family of kinesin-related proteins (KRPs). Polyclonal antisera raised against a bacterially expressed DSK1 fusion protein stained the diatom central spindle with a frequent bias toward the spindle midzone. Anti-DSK1 also blocked central spindle elongation in an in vitro assay. Inhibition of spindle elongation could be reversed by coincubating with the

Contract grant sponsor: NIH; Contract grant number: GM23238.

*Correspondence to: W.Z. Cande, Dept. of Molecular and Cell Biology, University of California, Berkeley, 341 Life Sciences Addition, Berkeley, CA94720-3200. E-mail: zcande@uclink4.berkeley.edu.

Received 23 March 1998; Accepted 6 August 1998

(ㄷ) 1998 Wiley-Liss, Inc. 
fusion protein against which anti-DSK1 was raised. These experiments illustrated that DSK1 is involved in spindle elongation and is likely the molecular motor responsible for pushing half-spindles apart during anaphase.

During the course of our studies, we observed that DSK1 seemed to grow more concentrated in the spindle midzone during anaphase, as would be expected for an anaphase B motor. DSK1 also seemed to remain in the spindle midzone upon the completion of anaphase B, after the bulk of the MTs had left the region. This observation suggests the existence of a non-MT spindle scaffold or matrix. The existence of such a matrix would have important implications for mechanisms of spindle function.

It is well known that MTs are not the only component responsible for the structural integrity of the mitotic spindle [Kuriyama and Nislow, 1992]. For example, spindles of marine invertebrate eggs from clams and sea urchins were shown to maintain their shape and birefringence even after the extraction of MTs from isolated mitotic apparatuses [Rebhun and Sander, 1967]. Bridges between MTs can be seen by electron microscopy in midzone cross-sections from many different mitotic spindles [Oakley and Heath, 1978; Ritter et al., 1978; McDonald et al., 1979; McDonald and Cande, 1989; McDonald, 1989; Ding et al., 1993; Winey et al., 1995]. These cross-bridges are thought to play a role in organizing the highly ordered square and hexagonal arrays of MTs that are seen in spindle midzones from diatoms to fungi to mammals [McDonald et al., 1979; McIntosh et al., 1979, 1985; Tippit et al., 1983, 1984; Ding et al., 1993; Mastronarde et al., 1993; Winey et al., 1995].

A spindle "matrix" independent of MTs has been identified consistently in the midzone (or interzone) of many mitotic spindles [McDonald, 1989]. It appears under the electron microscope as an osmiophilic, filamentous, or "fuzzy" material that is perhaps best visualized during midbody formation in metazoans [McIntosh and Landis, 1971; Mullins and Biesele, 1977] and in diatoms during the latter stages of spindle elongation [McDonald et al., 1977]. This material appears to accumulate in anticipation of cytokinesis, during the latter stages of spindle elongation.

In addition to its more obvious presence late in mitosis, the spindle matrix may also play roles in organizing spindle MTs at earlier stages. During anaphase spindle elongation in many organisms, for example, there is a change in the packing order of MTs in the spindle midzone that may involve spindle matrix protein [McDonald et al., 1979; Heath, 1980; Ding et al., 1993; Winey et al., 1995]. One can also infer that the matrix might play a role in the formation of the mitotic spindle during prophase and prometaphase.
Unfortunately, although several antigens show immunolocalization patterns at the spindle midzone [Fritzler et al., 1987; Kingwell et al., 1987; Pankov et al., 1990; Sellitto and Kuriyama, 1988; Kuriyama and Nislow, 1992], little is really known about the non-MT spindle matrix. In order to understand the functional role of these widely documented matrices, it will be necessary to determine their molecular composition. Toward this end, we use biochemical and cytological techniques to demonstrate that DSK1 is part of a matrix that can exist independently of the MTs of the half-spindles. As DSK1 has previously been shown to be involved in anaphase spindle elongation, this discovery has implications for both the structural organization of the mitotic spindle and the mechanism of anaphase spindle elongation.

\section{MATERIALS AND METHODS In Vitro Reactivation of Spindle Elongation}

For the study of DSK1 distribution during spindle elongation, two sets of synchronized permeabilized cells were centrifuged at $2,500 \mathrm{~g}$ for $5 \mathrm{~min}$ through $3 \mathrm{ml}$ of PMEG [50 mM 1,4-piperazinediethane sulfonic acid (PIPES) $\mathrm{pH} 7.0,5 \mathrm{mM} \mathrm{MgSO}$, $5 \mathrm{mM}$ EGTA, $40 \mathrm{mM}$ $\beta$-glycerophosphate, $1 \mu \mathrm{M}$ TROLOX, $1 \mathrm{mM}$ PMSF, $1 \mathrm{mM}$ dithiothreitol (DTT), $1 \mathrm{mM}$ phenylmethylsulfonyl fluoride (PMSF), and proteolytic inhibitors $\{1 \mu \mathrm{g} / \mathrm{ml}$ leupeptin, $1 \mu \mathrm{g} / \mathrm{ml}$ pepstatin $\mathrm{A}, 10 \mu \mathrm{g} / \mathrm{ml} \mathrm{N} \alpha$-benzoyl-Larginine methyl ester (BAME), $10 \mu \mathrm{g} / \mathrm{ml} \mathrm{N} \alpha$-p-tosyl-Larginine methyl ester (TAME), $10 \mu \mathrm{g} / \mathrm{ml} \mathrm{N}$-tosyl-Lphenylalanine chloromethyl ketone (TPCK), $10 \mu \mathrm{g} / \mathrm{ml}$ soybean trypsin inhibitor, $1 \mu \mathrm{g} / \mathrm{ml}$ aprotinin]] [Masuda et al., 1988] + 3\% dimethyl sulfonic acid (DMSO) onto poly-L-lysine-coated coverslips, then incubated in $100 \mu \mathrm{l}$ PMEG with (1) $0.05 \mathrm{mM}$ ATP or (2) $1 \mathrm{mM}$ GTP [Wein et al., 1996]. For a period of 4 min, one coverslip was fixed every 30 seconds for $10 \mathrm{~min}$ in $0.1 \%$ glutaraldehyde, $0.05 \%$ paraformaldehyde in PME $(50 \mathrm{mM}$ PIPES, $5 \mathrm{mM}$ $\mathrm{MgSO}_{4}, 5 \mathrm{mM}$ EGTA). All coverslips were reduced in $1 \mathrm{mg} / \mathrm{ml}$ sodium borohydride in $50 \% \mathrm{MeOH} / \mathrm{H}_{2} \mathrm{O}$ and blocked in $0.3 \% \mathrm{BSA} / \mathrm{PBS}$ for $20 \mathrm{~min}$. Coverslips were then incubated in appropriate antibodies for $1 \mathrm{~h}$ each: anti-DSK1 at $8 \mu \mathrm{g} / \mathrm{ml}$, a monoclonal mouse anti-sea urchin $\alpha$-tubulin (provided by Dr. D. Asai, Purdue University) at a 1:500 dilution, and then two secondary antibodies simultaneously, FITC-conjugated anti-rabbit (Cappel Research Reagents, Malvern, PA) at 1:100 and Texas-Red-conjugated anti-mouse (Jackson ImmunoResearch, West Grove, PA) at 1:200. Coverslips were incubated in PBS $+1 \mu \mathrm{g} / \mathrm{ml}$ 4',6-diamidino-2-phenylindole (DAPI) for $5 \mathrm{~min}$ before mounting on slides in 90\% glycerol containing $1 \mathrm{mg} / \mathrm{ml}$ 1,4-diazabicyclo[2,2,2]octane (Aldrich Chemical Co., Milwaukee, WI). 


\section{Optical Sectioning and Spindle Modeling}

Images were collected on a widefield optical sectioning microscope using an Olympus OM1 inverted microscope equipped with a $60 \times$ NA1.4 oil immersion lens (Olympus, Inc., Lake Success, NY) [Hiraoka et al., 1991]. Data was collected with a 12-bit charge-coupled device camera by automatically stepping through the cells at $0.2 \mu \mathrm{m}$ intervals; voxel $\mathrm{X}, \mathrm{Y}, \mathrm{Z}$ dimensions were $0.07,0.07,0.2 \mu \mathrm{m}$. Three-dimensional data stacks capturing entire spindles contained 30 sections each. Data stacks were subjected to three-dimensional constrained iterative deconvolution [Agard et al., 1989; Chen et al., 1995, 1996]. Data manipulation and examination were then performed on the deconvoluted data using the Priism software program [Chen et al., 1989, 1996]. The axial paths of the spindles were modeled such that a single line was made that passed through the center of the tubulin signal. A three-dimensional tube centered about that line contained the entire spindle, and was computationally extracted and straightened for analysis. The total intensity of each $0.1 \mu \mathrm{m}$ slice of this tube was determined and plotted. For average spindle intensities, the numbers within each spindle were first normalized to the brightest spindle point. Spindles were aligned by the brightest central point or dimmest central point, depending on spindle class, before averaging. Average points calculated from less than two spindles were eliminated, resulting in average spindle lengths shorter than most actual lengths.

\section{Spindle MT Extractions}

Isolated spindles in a total volume of $20 \mathrm{ml}$ PMEG were divided into two tubes and centrifuged through a $1 \mathrm{ml}$ cushion of PMEG $+40 \%$ sucrose at $16,000 \mathrm{~g}$ for 15 min. Each pellet was gently resuspended with $1 \mathrm{ml}$ of PBS (including $1 \mathrm{mM}$ PMSF, $1 \mathrm{mM}$ DTT, and proteolytic inhibitors) $+0.2 \%$ Tween- 20 or PBS $+0.2 \%$ Tween- $20+$ $4 \mathrm{mM} \mathrm{CaCl}_{2}$, and rotated at $4{ }^{\circ} \mathrm{C}$ for $1 \mathrm{~h}$. Samples were then centrifuged as above for $30 \mathrm{~min}$. Supernatants were removed and concentrated using Centricon-10 (Amicon, Danvers, MA) devices according to manufacturer's instructions. Pellets were resuspended in a volume equal to the final supernatant volumes using PBS $+0.5 \%$ SDS, then boiled for $10 \mathrm{~min}$ and centrifuged briefly in a microfuge to remove remaining cellular debris.

Equal volumes were loaded onto a $10 \%$ polyacrylamide gel, electrophoresed, then transferred to nitrocellulose by semi-dry blotting. The blots were blocked overnight at $4{ }^{\circ} \mathrm{C}$ with $5 \%$ non fat milk in PBS $+0.2 \%$ Tween-20 and then incubated with antibodies for $1 \mathrm{~h}$ at room temperature. Anti-DSK1 was used at $4 \mu \mathrm{g} / \mathrm{ml}$ and affinity-purified rabbit anti-soybean $\alpha$-tubulin (provided by Dr. R. Cyr, Penn State Univ.) at 1:500. HRPconjugated anti-rabbit secondary antibody (Jackson ImmunoResearch) was used at 1:5,000 and detected using ECL reagents (Amersham Corp., Arlington Heights, IL) according to the manufacturer's instructions.

\section{Coverslip MT Extractions}

In order to view cells in which MTs have been selectively extracted, permeabilized cells were spun down onto coverslips as described above. Solutions of PBS or PBS $+4 \mathrm{mM} \mathrm{CaCl}_{2}$ were added to the coverslips, which were then incubated for $2 \mathrm{~h}$ at $4^{\circ} \mathrm{C}$. ATP or GTP $(1 \mathrm{mM})$ were added to some samples for $10 \mathrm{~min}$ before fixation. Coverslips were processed as above for immunofluorescence. Slides were observed using a Zeiss Axiophot Photomicroscope with a Zeiss 100X Neofluar objective (Carl Zeiss, Inc., Thornwood, NY) with epifluorescence illumination. Photographs were taken on T-MAX 400 film (Eastman Kodak Co., Rochester, NY).

\section{RESULTS \\ Quantitative Three-Dimensional Analysis of DSK1 Distribution}

DSK1 was previously shown to be concentrated in the spindle midzone during in vitro anaphase spindle elongation and to remain in the midzone for a brief period of time after the half spindles had separated [Wein et al., 1996]. To more carefully examine the distribution of DSK1 during spindle elongation, we fixed permeabilized cells every 30 seconds for $10 \mathrm{~min}$ after the addition of $1 \mathrm{mM}$ GTP or low levels of ATP $(0.05 \mathrm{mM})$. At these nucleotide concentrations, spindle elongation proceeds at a slow rate [Hogan et al., 1992], that is, it takes more time for gaps to appear between the two half spindles. Each coverslip examined contains several hundred spindles, and the general effect of a nucleotide treatment over an entire coverslip can be quickly assessed [Hogan et al., 1992].

To more precisely measure the levels of tubulin and DSK1 along the lengths of spindles, we imaged entire spindles using quantitative 3-D microscopy, extracted a 3-D tube of data, and computationally determined the intensities in sequential slices along the tube. The result is a one-dimensional sequence of numbers representing the real-space intensity levels along the length of each spindle. While this method sacrifices the ability to measure any deviation in the radial symmetry of signals about the spindle axis, it provides complete quantitative and spatial signal distribution information for comparative analysis within and between spindles. 
This complete three-dimensional modeling and analysis was performed on 38 spindles at various stages of elongation. As diatom spindle populations cannot be precisely synchronized, spindles were selected based on a visual assessment from different coverslips fixed at different time points.

Figure 1 provides three examples of our threedimensional spindle modeling. Figure 1a shows a spindle before the addition of nucleotide. DSK1 shows a distinct midzone bias in this spindle, as noted previously [Wein et al., 1996]. Figure 1b shows a spindle treated with low levels of ATP. DSK1 has left the midzone region before the fixation of this spindle. Figure 1c shows a spindle treated with GTP. DSK1 remains longer in the midzone after the half-spindles have separated under the GTP treatment.

Figure 2 shows the composite results of this study. Spindles were grouped into different classes based on the distribution of their tubulin signal. The graphs are based on averages of all spindles in a given class after numbers were normalized to the brightest point in each spindle and aligned (see Materials and Methods).

Before half-spindles have separated (class 1), DSK1 shows a midzone bias. When half-spindles have just begun to separate (class 2), DSK1 peaks in the midzone, particularly in those spindles treated in the presence of GTP. By the time the tubulin intensity in the midzone has dropped to $40 \%$ or less of a spindle's peak intensity (class 4), DSK1 also markedly decreases in the midzone of ATP-treated spindles. In GTP-treated spindles, however, DSK1 staining is still concentrated in the midzone and at the ends of the half-spindles. Eventually, this midzone bias dissipates in GTP-treated spindles as well (class 5). Note that both treatments did not produce spindles in all classes. For example, ATP treatment did not produce any spindles in class 2.

Although concentrations of ATP and GTP were selected that support spindle elongation at similar rates [Hogan et al., 1992], we found that more half spindles had separated at earlier time points with the GTP treatment (data not shown). However, despite the higher number of midzone tubulin gaps with the GTP treatment, DSK1 left the midzone at a slower rate.

\section{Presence of DSK1 Does Not Depend on Spindle MTs}

In order to determine whether DSK1 is part of an insoluble spindle scaffold, we selectively extracted MTs to determine whether DSK1 was left behind. Permeabilized cells were incubated in a MT-destabilizing buffer containing $4 \mathrm{mM} \mathrm{CaCl}_{2}$. Figure 3 demonstrates that while almost all of the tubulin is extracted with a $1 \mathrm{~h} \mathrm{CaCl}_{2}$ treatment, no detectable amounts of DSK1 are present in the supernatant. DSK1 was not solubilized upon the depolymerization of MTs.

To determine what structure remains behind in these permeabilized cells, we performed a MT extraction after adhering cells to glass coverslips. By electron microscopy, we were unable to detect any MT-based spindles in this preparation, although we found several cells containing spindle-shaped flocculent material (data not shown). By immunofluorescence, DSK1 is seen to remain behind as part of a spindle-shaped structure even after the vast majority of spindle MTs have been depolymerized (Fig. 4). Two different tubulin antibodies known to react with diatom tubulin, as well as two different secondary antibodies, were used to confirm that spindle MTs could not be seen with the naked eye under the microscope. However, long exposures times and high contrast printing as shown here do reveal a trace of spindle MTs with the $\mathrm{CaCl}_{2}$ treatment. A subsequent nucleotide treatment with either $1 \mathrm{mM}$ ATP or $1 \mathrm{mM}$ GTP causes a further decrease in MT intensity, frequently below the detection limits of any conventional photographic enhancement methods (Fig. 4). DSK1 staining in this case is still prominent, but becomes less bar-like, taking on a flocculent quality and often looking like a ribbon.

\section{DISCUSSION}

By slowing down the rate of anaphase B movement in vitro, we have been able to fix and observe spindles during the process of elongation. Quantitative analysis of optically reconstructed spindles allowed us to make a clear description of the spatial rearrangements of DSK1 relative to tubulin at different stages of elongation. DSK1 accumulates in the spindle midzone during spindle elongation and remains in the spindle midzone even after the bulk of the spindle MTs have left the region. This effect is enhanced when GTP is used to support spindle elongation. Both the biochemical and cytological analyses of $\mathrm{CaCl}_{2}$ treatments show that DSK1 is left behind in a spindle-shaped bar when the vast majority of spindle MTs are extracted. These results provide evidence that DSK1 is part of a mitotic spindle matrix.

Uncertainty about the function of the non-MT mitotic spindle matrix stems from the lack of information concerning its molecular composition. One protein component that has been identified is a $50 \mathrm{kD}$ polypeptide from the detergent-resistant sea urchin egg cytomatrix [Raymond et al., 1987]. Notably, this polypeptide shares a characteristic with intermediate filaments in that it is insoluble in high ionic strength buffer solutions. Indeed, it was later shown that tektin, an intermediate filament 

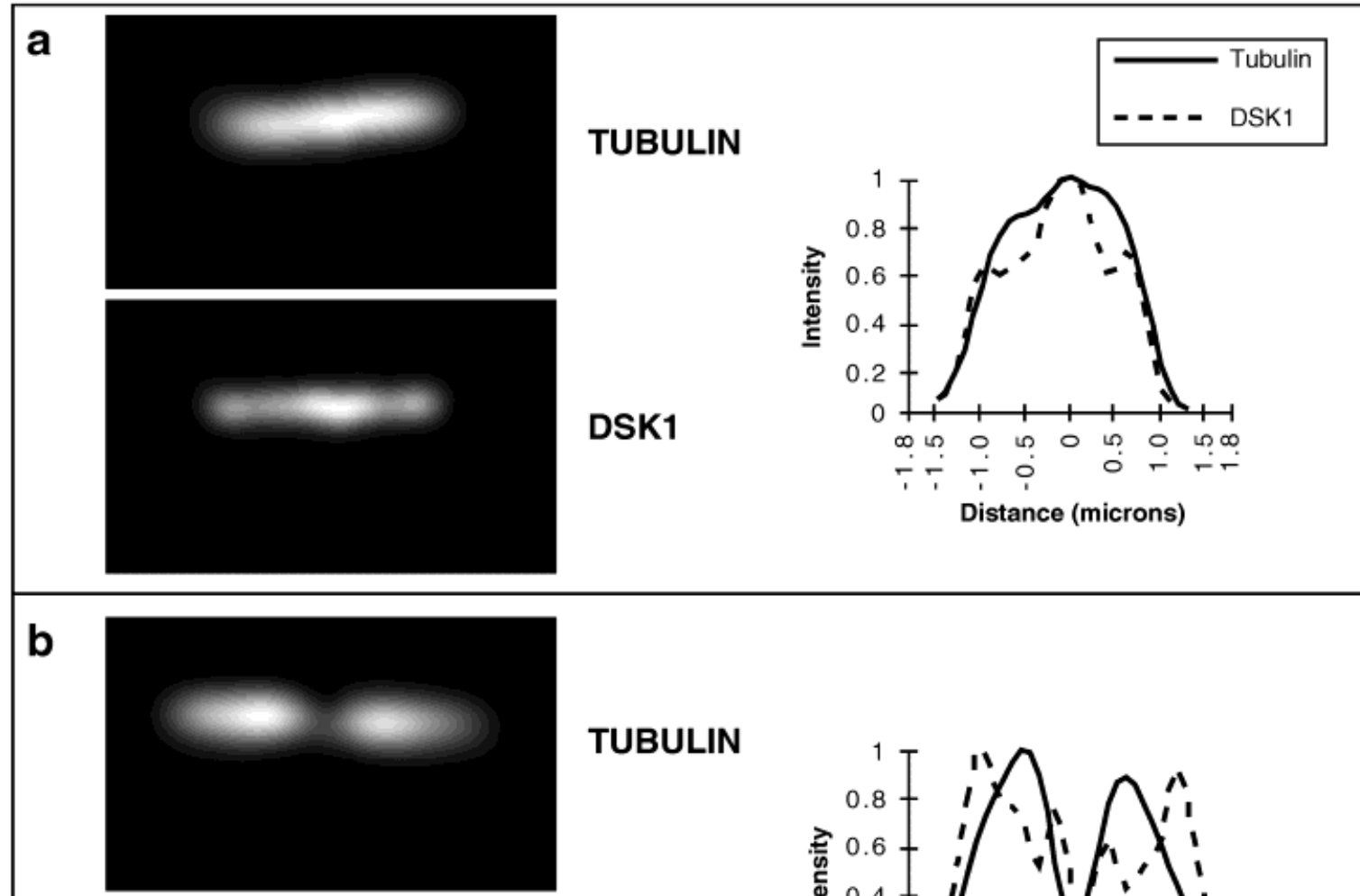

\section{TUBULIN}
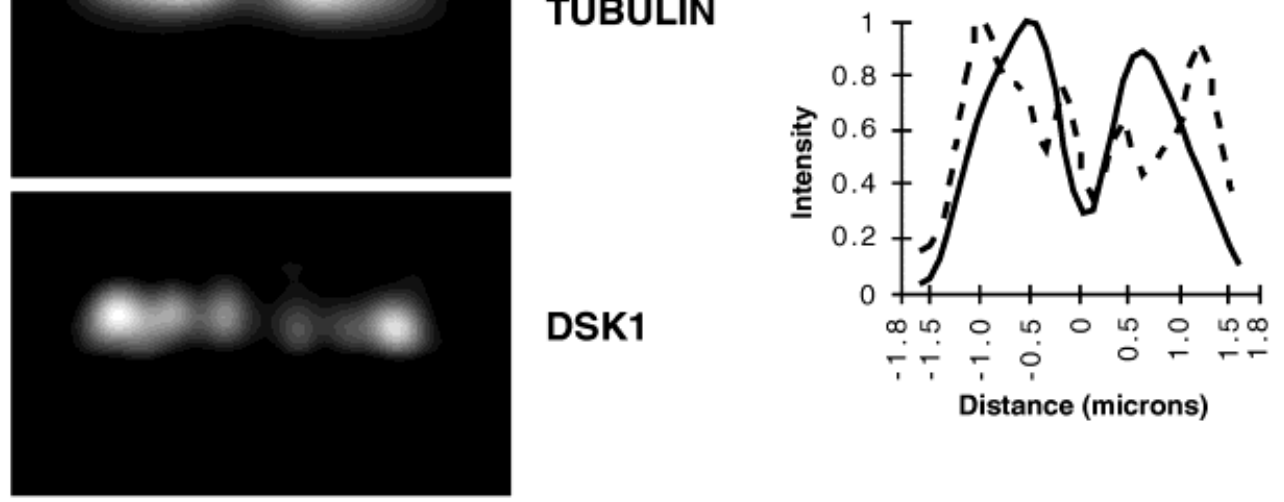

C

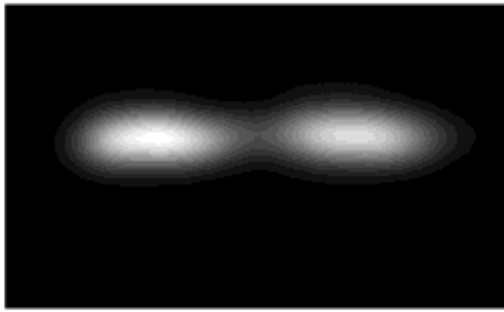

\section{TUBULIN}
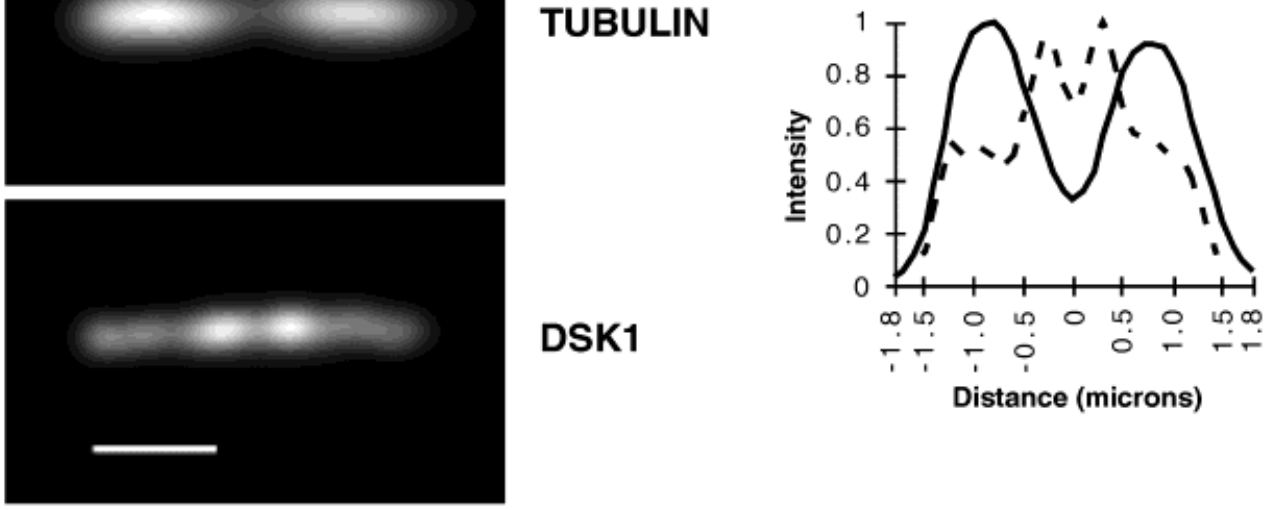

Fig. 1. Three-dimensional analysis of DSK1 and tubulin in the central spindle. All the light collected from sections through an entire three-dimensional spindle is combined into a single two-dimensional "through-focus projection" for each spindle. Graphs depict the corresponding intensity profiles of tubulin and DSK1. Numbers are normal-

ized to the brightest "slice" of each data set for graphing, with a maximum intensity of 1 (see Materials and Methods for a description of modeling and data manipulation). a: Spindle before the addition of nucleotide. b: Spindle after the addition of $0.05 \mathrm{mM}$ ATP. c: Spindle after the addition of $1 \mathrm{mM} \mathrm{GTP}$. Bar $=1 \mu \mathrm{m}$. 
a

class 1
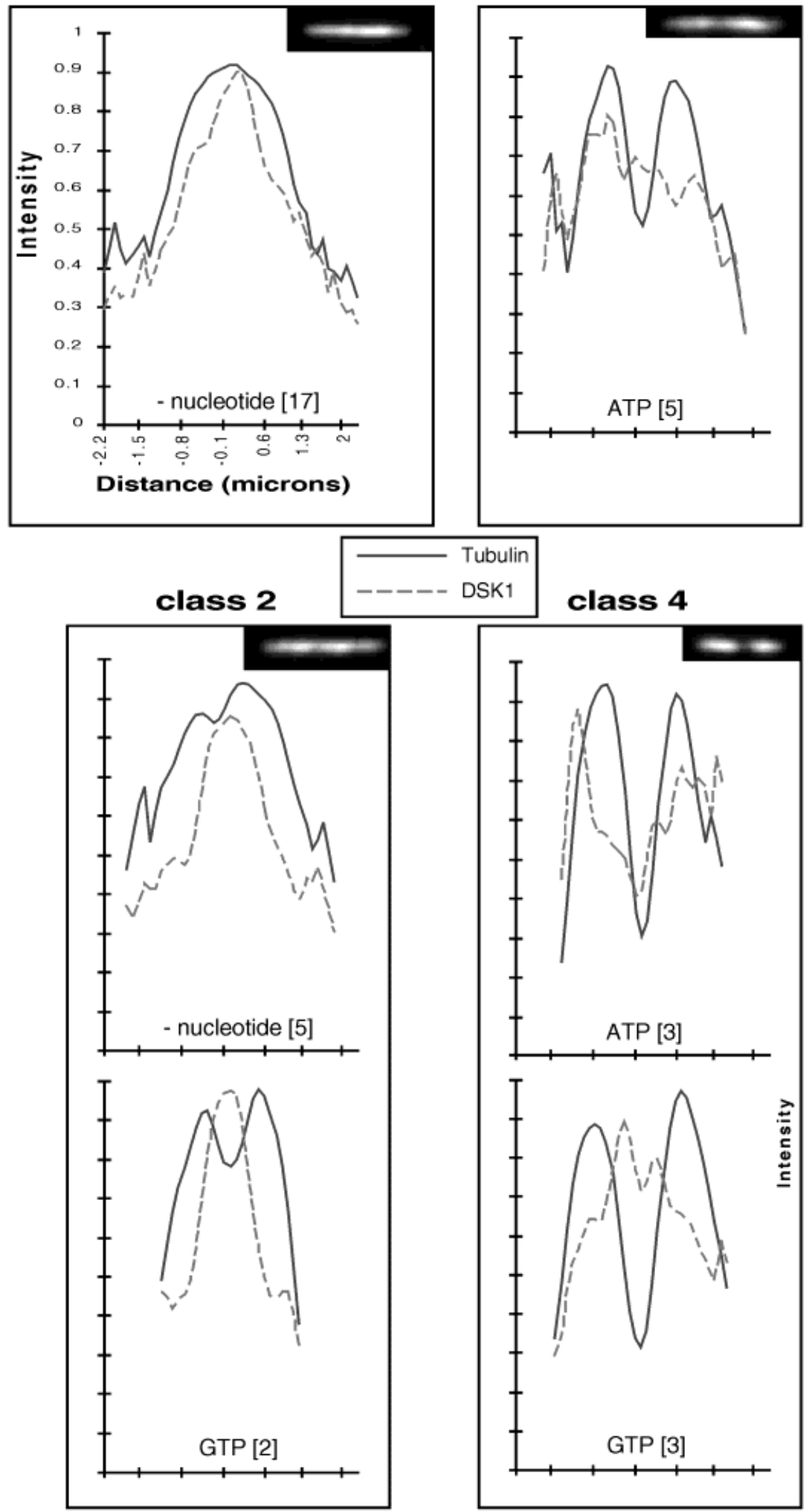

class 3

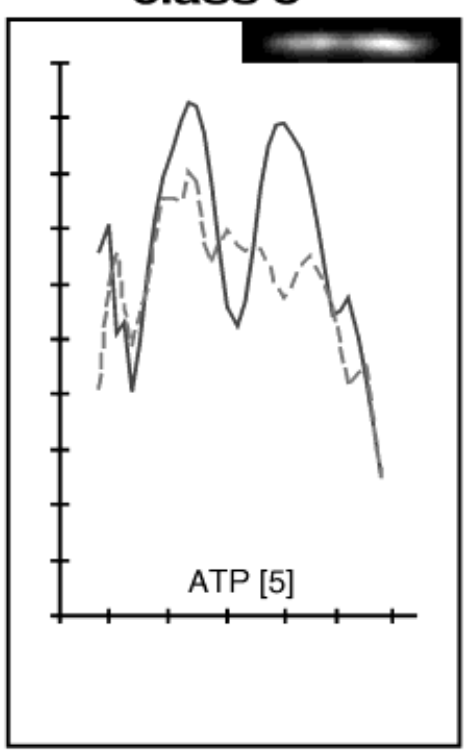

b
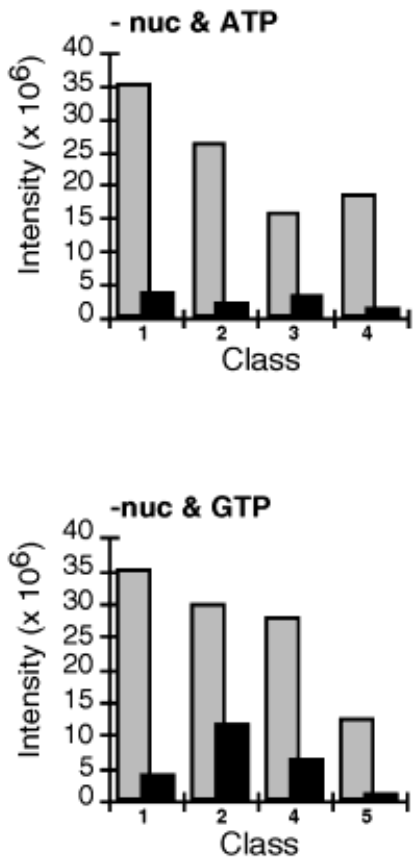

Tubulin

DSK1
Fig. 2. DSK1 remains in the midzone longer when spindles elongate in the presence of GTP. a: Intensity profiles from each class of spindle. An immunofluorescent image of the tubulin distribution in a representative spindle is displayed in the upper right-hand corner of the panel for each spindle class. Numbers are normalized for each spindle, the spindles are aligned by their centers, then the values at each point are averaged. Sample size is noted in brackets. Class 1, prior to detectable half- spindle separation. Class 2, two detectable peaks. Class 3, central dip at or below $60 \%$ of brightest spindle intensity. Class 4 , central dip at or below $40 \%$ of brightest spindle intensity. Note the comparative difference in DSK1 distribution between the two nucleotide treatments. Class 5 , central dip at or below $20 \%$ of brightest spindle intensity. b: Averages of the whole spindle intensities in each class. 


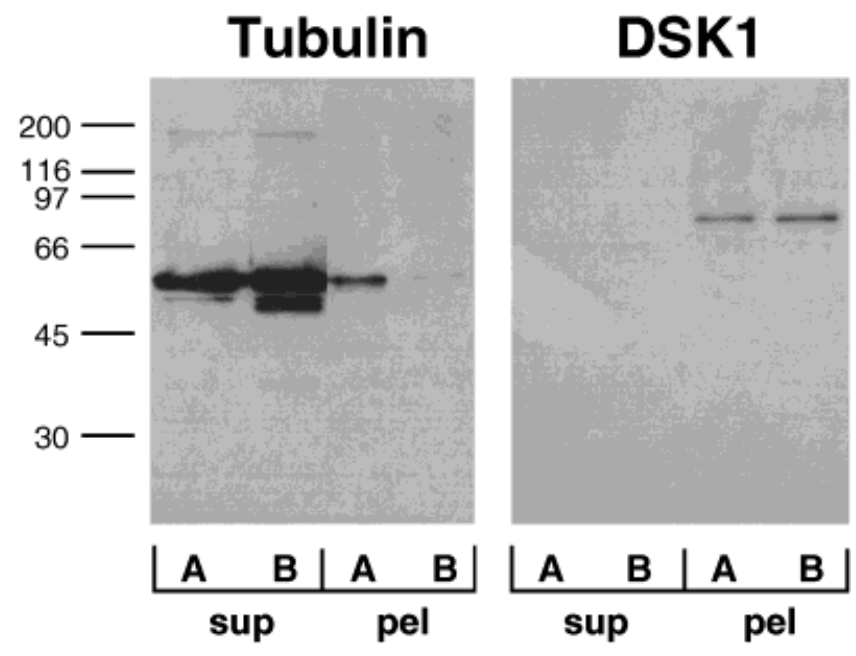

Fig. 3. DSK1 remains insoluble when spindle MTs are extracted. After a $\mathrm{CaCl}_{2}$ treatment, the vast majority of tubulin is found in the supernatant while DSK1 remains in the pellet. A: PBS treatment. B: 4 $\mathrm{mM} \mathrm{CaCl}{ }_{2}$ treatment, sup, supernatant; pel, pellet. Equal volumes were loaded in each lane.

protein, was part of the tubulin-depleted spindle remnants from clam eggs [Steffen and Linck, 1992].

Another possible candidate for a spindle matrix protein arose from studies using $\mathrm{CHO} 1$, a monoclonal antibody raised against mitotic spindles from Chinese hamster ovary cells. Immunolocalizations showed that the $\mathrm{CHO} 1$ antigen was restricted to the MTs at the spindle midzone [McIntosh and Landis, 1971; Sellitto and Kuriyama, 1988; Kuriyama and Nislow, 1992]. Injection of $\mathrm{CHO} 1$ antibody resulted in the loss of $\mathrm{CHO} 1$ antigen localization as well as a disorganization of spindle MTs [Nislow et al., 1990]. The CHO1 antigen has since been identified as a KRP that mediates the sliding of antiparallel MTs in vitro [Nislow et al., 1992]. CHO1 antigen in cultured mammalian cells has a native molecular mass of $362 \mathrm{kD}$, suggesting the existence of a large complex [Kuriyama et al., 1994]. This complex is likely involved in spindle elongation in vivo and may be a component of the spindle matrix. KRPs have also been identified as a component of the sea urchin spindle matrix; an antibody against kinesin was used to demonstrate the presence of KRPs in spindles, which had been completely extracted of microtubules by treatment with a $\mathrm{Ca}^{2+}$-containing buffer at $0^{\circ} \mathrm{C}$ [Leslie et al., 1987]. Although it was subsequently shown that the sea urchin kinesin was attached to spindle associated vesicles [Wright et al., 1991], this cannot be the case for DSK1 since vesicles are excluded from the densely packed microtubules of the diatom central spindle [Wein and Cande, unpublished data] and the spindles were detergent extracted during their isolation.
In diatoms, a possible midzone matrix antigen was identified using Stephanopyxis turris, but due to the difficulty of biochemical studies in the system, no specific protein was isolated and characterized [Wordeman and Cande, 1987]. Protein phosphorylation was shown to be necessary for spindle elongation in vitro in both $S$. turris [Wordeman and Cande, 1987] and in C. fusiformis [Hogan et al., 1993]. In S. turris, the ability of spindles to elongate can be maintained by incubating spindles in low levels of ATP $\gamma \mathrm{S}$, an ATP analog that results in the nonreversible phosphorylation of many proteins. An antibody to thiophosphorylated epitopes [Gerhart et al., 1985] then allows for the visualization of thiophosphorylated proteins in spindles treated with ATP $\gamma \mathrm{S}$. The spindle overlap zone is labeled under these conditions, as well as the kinetochores and spindle poles in some cells [Wordeman and Cande, 1987]. This staining pattern was also demonstrated in $C$. fusiformis using similar techniques [Hogan et al., 1992]. During spindle elongation, the thiophosphorylated midzone proteins do not move out of the overlap zone with the sliding MTs [Wordeman et al., 1989].

The staining pattern of DSK1 in the $C$. fusiformis spindle during metaphase and anaphase is similar to that found for thiophosphorylated epitopes when high concentrations of ATP $\gamma \mathrm{S}$ are added to the system [Hogan et al., 1992] (personal observations). Upon spindle elongation, DSK1 remains in the spindle midzone, much as the thiophosphorylated epitope does. The thiophosphorylated epitope seen in the spindle, then, may be located on the DSK1 polypeptide or on another polypeptide associated with DSK1. Unfortunately, immunoblots of $C$. fusiformis protein extracts using the thiophosphorylated epitope antibody are too complex to interpret. A direct visual comparison of the DSK1 and thiophosphorylated epitope distribution patterns during spindle elongation is problematic as well; although $\mathrm{ATP} \gamma \mathrm{S}$ does not support spindle elongation in S. turris [Cande and McDonald, 1986], it does to a limited extent in C. fusiformis [Hogan et al., 1992], making thiophosphorylation experiments in C. fusiformis difficult to interpret.

Figure 5 summarizes our current understanding of DSK1 distribution during in vitro anaphase B. Previous studies from our laboratory have shown a midzone bias in DSK1 distribution before the addition of exogenous nucleotide. We have argued in the past that this midzone bias appeared before spindles started to elongate. The results of the three-dimensional spindle modeling described in this paper, however, were quite revealing. Several spindles on coverslips untreated with nucleotide were classified as class 2 based on their tubulin distributions, confirming our belief that the mitotic synchronization procedure used on these diatom cells does not create 


\section{Tubulin}

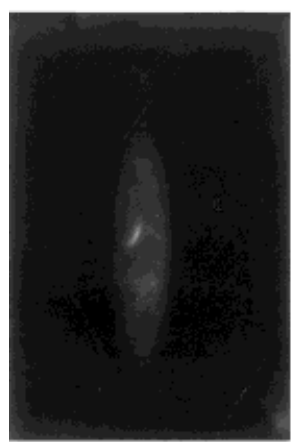

PBS
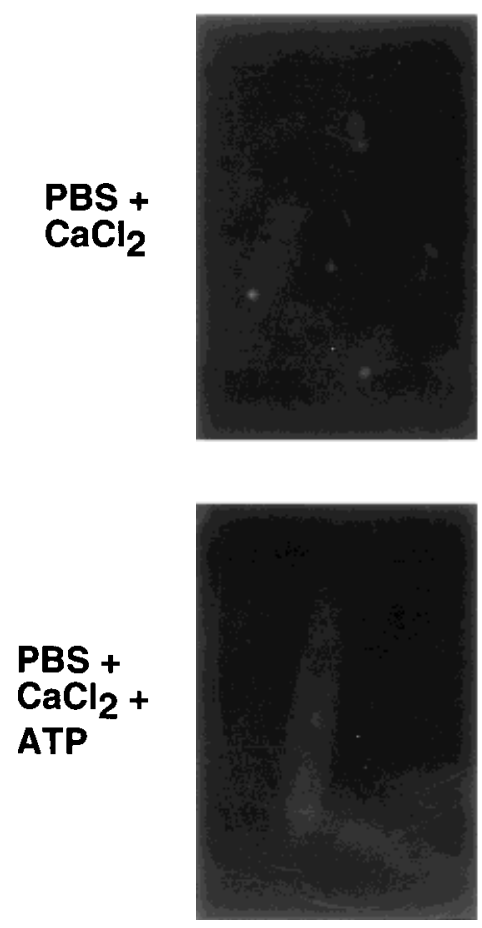

DSK1
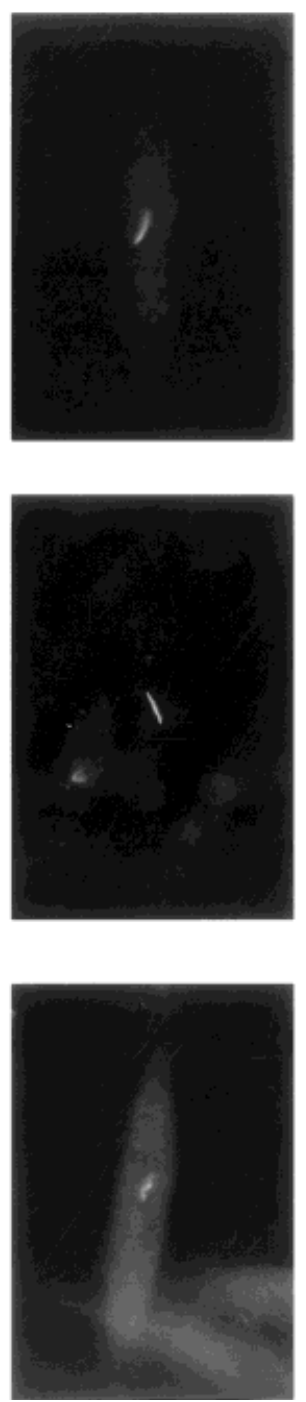

DAPI
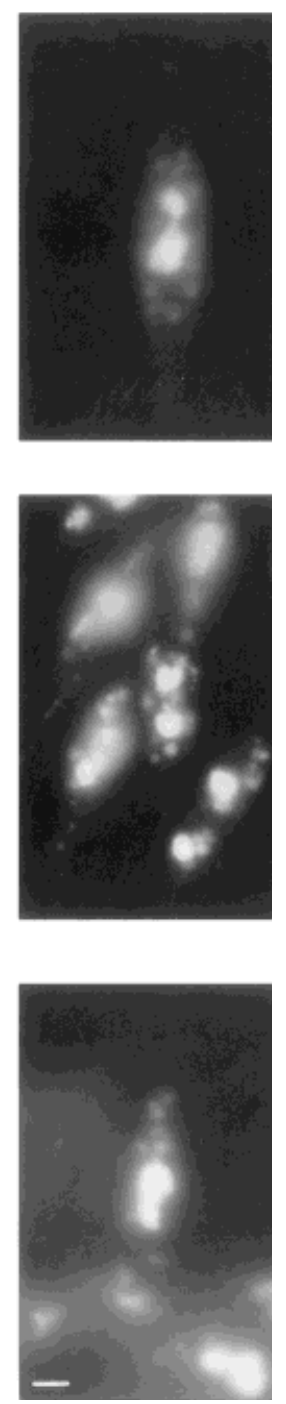

Fig. 4. DSK1 remains as a spindle-like bar even after spindle MTs have been removed. Cells were incubated in control buffer or $4 \mathrm{mM} \mathrm{CaCl}_{2}$ for $2 \mathrm{~h}$. A portion of cells were incubated in $1 \mathrm{mM}$ ATP for the last 10 min. Staining with anti-DSK1 was visualized with FITC-conjugated secondary antibody. Tubulin was visualized with anti- $\alpha$-tubulin antibody and a Texas-Red-conjugated secondary antibody. DNA was visualized with DAPI. Bar $=3 \mu \mathrm{m}$.

a true metaphase block and that a certain number of spindles in the population are already in the process of elongating before the addition of exogenous nucleotide. These spindles may have been in the process of elongating when their cells were permeabilized, or they may have begun elongating using the residual nucleotides in solution, thereby accounting for the midzone bias we have seen in DSK1 distribution before nucleotide addition. We now think that it is likely DSK1 does not display a midzone bias until spindle elongation actually begins.

As elongation proceeds, DSK1 moves toward the plus ends of MTs, collecting in the spindle midzone. As the half-spindles slide apart, DSK1 is found mostly between the bulk of separating MTs. After the halfspindles have slid completely apart, DSK1 eventually leaves the spindle midzone, a second nucleotidedependent step.

DSK1 has previously been shown to be involved in spindle elongation [Wein et al., 1996], yet its precise role is not yet understood. The motor may directly crossbridge antiparallel MTs to generate movement, using the matrix as a tethering scaffold to stay in the midzone as MTs slide through, or alternatively may push the half-spindles apart by using the spindle matrix as a structural support. It is 

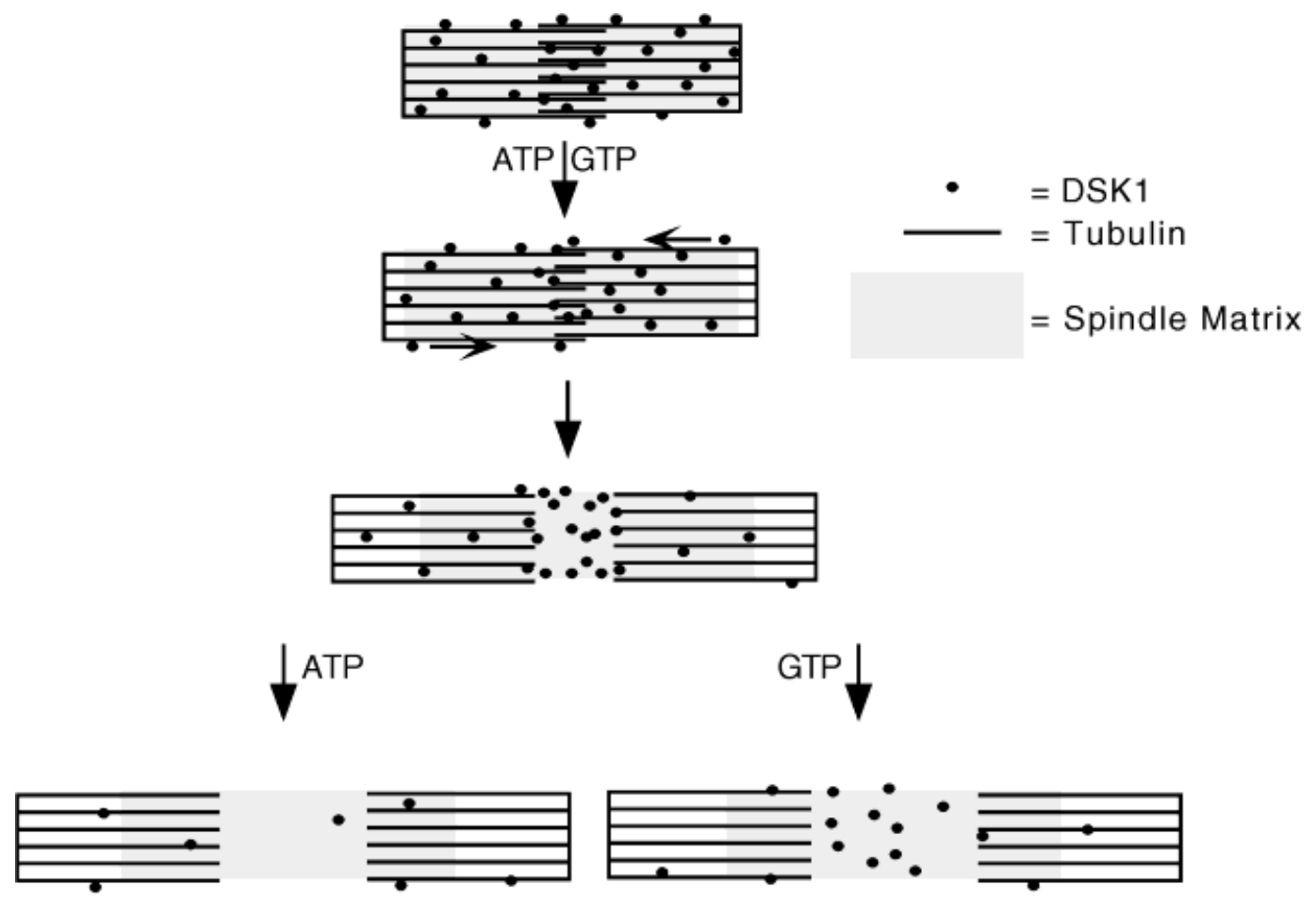

Fig. 5. Summary of changes in DSK1 distribution during anaphase B. DSK1 moves toward the plus ends of MTs in the central spindle as anaphase begins. From the ends of the half-spindles, DSK1 moves into the spindle midzone, where it associates with (or is itself a part of) the spindle matrix and plays a role in spindle elongation. After the half-spindles have slid completely apart, DSK1 then leaves the spindle midzone. This final release of DSK1 occurs at different rates with GTP and ATP.

also possible that DSK1 may promote plus-end MT depolymerization, an activity shown for XKCM1, a related KRP from Xenopus [Walczak et al., 1996]. However, this explanation seems unlikely, as previous work from our lab has shown that elongating spindles maintain biotinylated tubulin caps throughout in vitro spindle elongation [Hogan et al., 1992]. Unfortunately, a motor fragment of DSK1 expressed in bacteria [Wein et al., 1996] posed serious solubility problems and exhibited very limited in vitro activity. In order to more directly explore the role of DSK1 in spindle elongation and address the molecular composition of the spindle matrix, it will be necessary to purify native DSK1.

It has been speculated that spindle matrix proteins play a role as early as prometaphase in organizing the mitotic spindle. While the growing MTs provide directionality to the forming spindle, matrix components may bind to MTs and organize them into the highly ordered square and hexagonal arrays seen in the metaphase and anaphase diatom spindle. During anaphase spindle elongation, the spindle matrix can then serve as a scaffold to tether MT motors in the midzone while MTs slide through and grow. Such a role for the spindle matrix has been proposed many times before and is implied by the experiments discussed above [Wordeman and Cande, 1987; Cande et al., 1989], but this is the first demonstration that a protein known to be involved in anaphase spindle elongation is indeed part of, or attached to, an insoluble scaffold in the mitotic spindle.

\section{ACKNOWLEDGMENTS}

J.W. Sedat and D.A. Agard allowed us the use of the three-dimensional light microscope workstation at UCSF for three-dimensional imaging. We thank Steven E. Ruzin at the NSF Center of Plant Developmental Biology for the use of the Zeiss Axiophot Photomicroscope. We also thank So-ching Brazer, Barbara Brady, and the other members of the laboratory for intellectual discussions and for reviewing this manuscript. This work was supported by NIH grant GM23238.

\section{REFERENCES}

Agard, D.A., Hiraoka, Y., Shaw, P. and Sedat, J.W. (1989): Fluorescence microscopy in three dimensions. Methods Cell Biol. 30:353-377. 
Cande, W.Z., and McDonald, K.L. (1986): Physiological and ultrastructural analysis of elongating mitotic spindles reactivated in vitro. J. Cell Biol. 103:593-604.

Cande, W.Z., Baskin, T., Hogan, C., McDonald, K.L., Masuda, H., and Wordeman, L. (1989): In vitro analysis of anaphase spindle elongation. In Warner, F.D., McIntosh, J.R. (eds.): "Cell Movement, Volume 2: Kinesin, Dynein, and Microtubule Dynamics." New York: Alan R. Liss, Inc., pp. 441-452.

Chen, H., Sedat, J.W., and Agard, D.A. (1989): Manipulation, display, and analysis of three-dimensional biological images. In Pawley, J.B. (ed.): "The Handbook of Biological Confocal Microscopy." Madison, WI: IMP Press, pp. 153-165.

Chen, H., Swedlow, J., Grote, M., Sedat, J.W., and Agard, D.A. (1995): The collection, processing, and display of digital threedimensional images of biological specimens. In Pawley, J.B. (ed.): "The Handbook of Biological Confocal Microscopy." 2nd ed. New York: Plenum Press, pp. 197-210.

Chen, H., Hughes, D.D., Chan, T.-A., Sedat, J.W., and Agard, D.A. (1996): IVE (Image Visualization Environment): A software platform for all three-dimensional microscopy applications. J. Struct. Biol. 116:56-60.

Ding, R., McDonald, K.L., and McIntosh, J.R. (1993): Threedimensional reconstruction and analysis of mitotic spindles from the yeast Schizosaccharomyces pombe. J. Cell Biol. 120:141-151.

Fritzler, M.J., Ayer, L.M., Gohill, J., O'Connor, C., Laxer, R.M., and Humbel, R.-L. (1987): An antigen in metaphase chromatin and the midbody of mammalian cells binds to scleroderma sera. J. Rheum. 14:291-294.

Gerhart, J., Cyert, M., and Kirschner, M. (1985): M-phase promoting factors from eggs of Xenopus laevis. Cytobios. 43:335-347.

Heath, B. (1980): Variant mitoses in lower eukaryotes: Indicators of the evolution of mitosis? Int. Rev. Cytol. 64:1-80.

Hiraoka, Y., Swedlow, J.R., Paddy, M.R., Agard, D.A., and Sedat, J.W. (1991): Three-dimensional multiple-wavelength fluorescence microscopy for the structural analysis of biological phenomena. Semin. Cell Biol. 2:153-165.

Hogan, C.J., Stephens, L., Shimizu, T., and Cande, W.Z. (1992): Physiological evidence for the involvement of a kinesin-related protein during anaphase spindle elongation in diatom central spindles. J. Cell Biol. 119:1277-1286.

Hogan, C.J., Neale, P.J., Lee, M., and Cande, W.Z. (1993): The diatom central spindle as a model system for studying antiparallel microtubule interactions during spindle elongation in vitro. Methods Cell Biol. 39:277-292.

Kingwell, B., Fritzler, M.J., Decoteau, J., and Rattner, J.B. (1987): Identification and characterization of a protein associated with the stembody using autoimmune sera from patients with systemic sclerosis. Cell Motil. Cytoskeleton 8:360-367.

Kuriyama, R., and Nislow, C. (1992): Molecular components of the mitotic spindle. BioEssays 14:81-88.

Kuriyama, R., Dragas-Granoic, S., Maekawa, T., Vassilev, A., Khodjakov, A., and Kobayashi, H. (1994): Heterogeneity and microtubule interaction of the $\mathrm{CHO} 1$ antigen, a mitosis-specific kinesinlike protein. J. Cell Sci. 107:3485-3499.

Leslie, R.J., Hird, R.B., Wilson, L., McIntosh, J.R., and Scholey, J.M. (1987): Kinesin is associated with a nonmicrotubule component of sea urchin mitotic spindles. Proc. Natl. Acad. Sci. U.S.A. 84:2771-2775.

Mastronarde, D.N., McDonald, K.L., Ding, R., and McIntosh, J.R. (1993): Interpolar spindle microtubules in PTK cells. J. Cell Biol. 123:1475-1489.
Masuda, H., McDonald, K.L., and Cande, W.Z. (1988): The mechanism of anaphase spindle elongation: Uncoupling of tubulin incorporation and microtubule sliding during in vitro spindle reactivation. J. Cell Biol. 107:623-633.

McDonald, K. (1989): Mitotic spindle ultrastructure and design. In Hyams, J.S., Brinkley, B.R. (eds.): "Mitosis: Molecules and Mechanisms." London: Academic Press, pp. 1-38.

McDonald, K.L., and Cande, W.Z. (1989): Diatoms and the mechanism of anaphase spindle elongation. In Coleman, A.W., Goff, L.J., Stein-Taylor, J.R. (eds.): "Algae as Experimental Systems." New York: Alan R. Liss, Inc., pp. 3-18.

McDonald, K., Pickett-Heaps, J.D., McIntosh, J.R., and Tippit, D.H. (1977): On the mechanism of anaphase spindle elongation in Diatoma vulgare. J. Cell Biol. 74:377-388.

McDonald, K., Edwards, M.K., and McIntosh, J.R. (1979): The cross-sectional structure of the central mitotic spindle of Diatoma vulgare: Evidence for specific interactions between antiparallel microtubules. J. Cell Biol. 83:443-461.

McIntosh, J.R., and Landis, S.C. (1971): The distribution of spindle microtubules during mitosis in cultured human cells. J. Cell Biol. 49:468-497.

McIntosh, J.R., McDonald, K.L., Edwards, M.K., and Ross, B.M. (1979): Three-dimensional structure of the central mitotic spindle of Diatoma vulgare. J. Cell Biol. 83:428-442.

McIntosh, J.R., Roos, U.-P., Neighbors, B., and McDonald, K.L. (1985): Architecture of the microtubule components of mitotic spindles from Dictyostelium discoideum. J. Cell Sci. 75:93-129.

Mullins, J.M., and Biesele, J.J. (1977): Terminal phase of cytokinesis in D-98s cells. J. Cell Biol. 73:672-684.

Nislow, C., Sellitto, C., Kuriyama, R., and McIntosh, J.R. (1990): A monoclonal antibody to a mitotic microtubule-associated protein blocks mitotic progression. J. Cell Biol. 111:511-522.

Nislow, C., Lombillo, V.A., Kuriyama, R., and McIntosh, J.R. (1992): A plus-end-directed motor enzyme that moves antiparallel microtubules in vitro localizes to the interzone of mitotic spindles. Nature 359:543-547.

Oakley, B.R., and Heath, I.B. (1978): The arrangement of microtubules in serially sectioned spindles of the alga Cryptomonas. J. Cell Sci. 31:53-70.

Pankov, R., Lemieux, M., and Hancock, R. (1990): An antigen located in the kinetochore region in metaphase and on polar microtubule ends in the midbody region in anaphase, characterized using a monoclonal antibody. Chromosoma 99:95-101.

Pickett-Heaps, J.D., and Tippit, D.H. (1978): The diatom spindle in perspective. Cell 14:455-467.

Raymond, M.-N., Foucault, G., Renner, M., and Pudles, J. (1987): Isolation of a $50 \mathrm{kDa}$ polypeptide from the detergent-resistant unfertilized sea urchin egg cytomatrix and evidence for its change in organization during mitosis. Eur. J. Cell Biol. 45:302-310.

Rebhun, L.I., and Sander, G. (1967): Ultrastructure and birefringence of the isolated mitotic apparatus of marine eggs. J. Cell Biol. 34:859-883.

Ritter, H., InouÈ, S., and Kubai, D.F. (1978): Mitosis in Barbulanympha. I. Spindle structure, formation, and kinetochore engagement. J. Cell Biol. 77:638-654.

Sellitto, C., and Kuriyama, R. (1988): Distribution of a matrix component of the midbody during the cell cycle in Chinese hamster ovary cells. J. Cell Biol. 106:431-439.

Steffen, W., and Linck, R.W. (1992): Evidence for a non-tubulin spindle matrix and for spindle components immunologically related to tektin filaments. J. Cell Sci. 101:809-822. 
224

\section{Wein et al.}

Tippit, D.H., Pillus, L., and Pickett-Heaps, J.D. (1983): Near neighbor analysis of spindle microtubules in the alga Ochromonas. Eur. J. Cell Biol. 30:9-17.

Tippit, D.H., Fields, C.T., O’Donnell, K.L., Pickett-Heaps, J.D., and McLaughlin, D.J. (1984): The organization of microtubules during anaphase and telophase spindle elongation in the rust fungus Puccinia. Eur. J. Cell Biol. 34:34-44.

Walczak, C.E., Mitchison, T.J., and Desai, A. (1996): XKCM1: A Xenopus kinesin-related protein that regulates microtubule dynamics during mitotic spindle assembly. Cell 84:37-47.

Wein, H., Foss, M., Brady, B., and Cande, W.Z. (1996): DSK1, a novel kinesin-related protein from the diatom Cylindrotheca fusiformis that is involved in anaphase spindle elongation. J. Cell Biol. 133:595-604.

Winey, M., Mamay, C.L., O’Toole, E.T., Mastronarde, D.N., Giddings,
Jr., T.H., McDonald, K.L., and McIntosh, J.R. (1995): Threedimensional ultrastructural analysis of the Saccharomyces cerevisiae mitotic spindle. J. Cell Biol. 129:1601-1615.

Wordeman, L., and Cande, W.Z. (1987): Reactivation of spindle elongation in vitro is correlated with the phosphorylation of a $205 \mathrm{kD}$ spindle-associated protein. Cell 50:535-543.

Wordeman, L., Masuda, H., and Cande, W.Z. (1989): Distribution of a thiophosphorylated spindle midzone antigen during spindle reactivation in vitro. J. Cell Sci. 93:279-285.

Wright, B.D., Henson, J.H., Wedamen, K.P., Willey, P.J., Morand, J.N., and Scholey, J.M. (1991): Subcellular localization and sequence of sea urchin heavy chain: Evidence for its association with membranes in mitotic apparatus and interphase cytoplasm. J. Cell Biol. 113:817-833. 